\title{
Tỷ lệ hội chứng dễ bị tổn thương trên bệnh nhân cao tuổi tại khoa cấp cứu bệnh viện lão khoa trung ương
}

\author{
Nguyễn Trung Anh ${ }^{1,2, ~}$, Đặng Thị Xuân ${ }^{3}$, Thái Sơn² ${ }^{2}$ Vũ Thị Thanh Huyền ${ }^{1,2}$ \\ ${ }^{1}$ Bệnh viện Lão khoa Trung ương

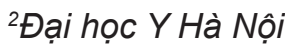 \\ ${ }^{3}$ Bệnh viện Bạch Mai
}

Hội chứng dễ bị tổn thương rất phổ biến ở người cao tuổi. Do vậy, chúng tôi tiến hành nghiên cứu này để xác định tỷ lệ hội chứng dễ bị tổn thương ở bệnh nhân cao tuổi điều trị tại khoa cấp cứu Bệnh viện Lão khoa Trung ương. Nghiên cứu được tiến hành theo phương pháp nghiên cứu mô tả cắt ngang tại khoa Cấp cứu Bệnh viện Lão khoa Trung ương, từ 10/2015 đến 10/2016 trên bệnh nhân từ 60 tuổi trở lên. Các biến số gồm: Đặc điểm chung và hội chứng dễ bị tổn thương đánh giá theo tiêu chuẩn Fried gồm 5 tiêu chí. Tổng số 389 bệnh nhân với độ tuổi trung bình là $79,1 \pm 8,9$. Tỉ lệ bệnh nhân có hội chứng dễ bị tổn thương chiếm $68,4 \%$. Trong 5 tiêu chí của hội chứng dễ bị tổn thương, tỉ lệ người có tốc độ đi bộ chậm cao nhất chiếm 85,5\%. Nhóm tuổi $\geq 80$ tuổi có tỉ lệ bị hội chứng dễ bị tổn thương cao nhất với 82,2\% ( $p<0,05)$. Tỉ lệ bệnh nhân tại khoa Cấp cứu mắc hội chứng dễ bị tổn thương khá cao đặc biệt trên nhóm bệnh nhân trên 80 tuổi. Do vậy cần sàng lọc thường quy trên người cao tuổi điều trị tại khoa cấp cứu.

Từ khóa: hội chứng dễ bị tổn thương, người cao tuổi, khoa cấp cứu, Việt Nam.

\section{I. ĐẠT VẤN ĐÊ}

Theo các số liệu gần đây từ Liên hợp quốc, dân số trên 60 tuổi ở các nước phát triển dự kiến sẽ tăng thêm 45\% vào năm 2050: Từ 287 triệu người trong 2013 tăng lên 417 triệu người vào năm 2050. Tại các nước đang phát triển, đối tượng dân số này sẽ còn tăng đáng kể hơn, dự kiến từ 554 triệu năm 2013 lên 1,6 tỷ vào năm 2050. Vào năm 2050, tỷ trọng dân số cao tuổi tại nước ta sẽ tăng gần gấp bốn lần hiện nay. Dự kiến năm 2017 dân số trên 60 tuổi chạm ngưỡng $10 \%$ tổng dân số, Việt Nam đã chính thức bước vào giai đoạn già hóa dân số. ${ }^{1}$

Hội chứng dễ bị tổn thương (Frailty) là một hội chứng lão khoa phổ biến, xảy ra do sự tích tụ của quá trình suy giảm chức năng của nhiều hệ

Tác giả liên hệ: Nguyễn Trung Anh

Trường Đại học Y Hà Nội

Email: trunganhvlk@gmail.com

Ngày nhận: 12/03/2021

Ngày được chấp nhận: 07/04/2021 thống cơ quan trong cơ thể. ${ }^{2}$ Điều này dẫn đến nhiều hậu quả bất lợi cho người cao tuổi như bị phụ thuộc nhiều hơn trong các hoạt động của cuộc sống hàng ngày, như ngã, khuyết tật, tăng tỷ lệ mắc các bệnh cấp tính, tăng tỷ lệ bệnh nhân điều trị trong khoa hồi sức cấp cứu, phục hồi chậm và không hoàn toàn từ các bệnh cấp tính và tử vong. ${ }^{3}$ Đặc biệt sự suy giảm chức năng hoạt động là một kết quả bất lợi của hội chứng dễ bị tổn thương và đó đặt một gánh nặng cho người cao tuổi, các nhà cung cấp dịch vụ chăm sóc và hệ thống chăm sóc sức khỏe. ${ }^{4}$

Song hành cùng già hóa dân số, số lượng bệnh nhân cao tuổi có tình trạng suy giảm chức năng và các bệnh cấp tính ngày càng gia tăng. Tác giả Stiffler đã khái quát sự mệt mỏi, kiệt sức là những triệu chứng phổ biến nhất để người cao tuổi phải đi khám cấp cứu, kèm theo sự hạn chế chức năng sinh hoạt hàng ngày. Các bệnh cấp tính, triệu chứng tăng lên của các bệnh mạn tính hoặc chấn thương, cũng là các 
lý do để người cao tuổi phải đi khám cấp cứu. ${ }^{5}$ Do đó các nghiên cứu gần đây tập trung tìm ra công cụ dự đoán, sàng lọc, ngăn chặn những kết quả bất lợi sau khi bệnh nhân phải điều trị tại các đơn vị cấp cứu. Theo Stiffler và cộng sự, hội chứng dễ bị tổn thương (HCDBTT) khá phổ biến ở các bệnh nhân điều trị tại khoa cấp cứu (20\%) và có liên quan với suy giảm chức năng ở người cao tuổi. ${ }^{5}$ Tỷ lệ mắc hội chứng này dao động từ 4,0\% đến $59,1 \%$, tùy thuộc vào cộng đồng dân số nghiên cứu và tiêu chuẩn đánh giá hội chứng dễ bị tổn thương. ${ }^{6}$ Các nghiên cứu cũng cho thấy người cao tuổi xuất hiện hội chứng dễ bị tổn thương có nguy cơ cao bị phụ thuộc chức năng hoạt động hàng ngày hơn so với người cao tuổi không có hội chứng này.

Tại Việt Nam đến nay vẫn chưa có một nghiên cứu nào được công bố về hội chứng dễ bị tổn thương trên các bệnh nhân tại khoa cấp cứu. Do vậy chúng tôi tiến hành nghiên cứu nhằm xác định lệ hội chứng dễ bị tổn thương trên bệnh nhân cao tuổi tại khoa Cấp cứu, Bệnh viện Lão khoa Trung ương.

\section{II. ĐÓl TƯỢNG VÀ PHƯO'NG PHÁP}

\section{1. Đối tượng}

Đối tượng nghiên cứu là bệnh nhân từ 60 tuổi trở lên điều trị tại Khoa Cấp cứu Bệnh viện Lão khoa Trung Ương.

\section{Phương pháp}

Tiêu chuẩn lựa chọn

Các bệnh nhân phải có tình trạng tinh thần tỉnh táo, có khả năng nghe và trả lời phỏng vấn.

Bệnh nhân đồng ý hợp tác nghiên cứu.

Tuổi $\geq 60$ tuổi điều trị tại Khoa Cấp cứu.

Tiêu chuẩn loại trừ

Chống chỉ định vận động và hoạt động thể lực của bác sĩ điều trị cho bệnh nhân (suy hô hấp, nhồi máu cơ tim...).

Không đồng ý tham gia nghiên cứu.

\section{Thiết kế nghiên cứu}

Nghiên cứu được tiến hành theo phương pháp nghiên cứu mô tả cắt ngang.

Cỡ mẫu và phương pháp chọn mẫu

Công thức tính cỡ mẫu :

$$
n=\begin{gathered}
Z_{1-\alpha / 2}^{2} p(1-p) \\
d^{2}
\end{gathered}
$$

Cỡ mẫu ước tính là $\mathrm{n}=229$ bệnh nhân. ${ }^{11}$

Phương pháp chọn mẫu toàn bộ các bệnh nhân vào khoa Cấp cứu đủ tiêu chuẩn lựa chọn.

Địa điểm và thời gian nghiên cứu

Nghiên cứu được tiến hành tại Khoa Cấp cứu Bệnh viện Lão Khoa Trung ương.

Thời gian nghiên cứu: Từ tháng 10 năm 2015 đến tháng 10 năm 2016 (12 tháng).

Biến số, chỉ số và các tiêu chuẩn đánh giá.

Thông tin về đối tượng nghiên cứu: tuổi, giới, cân nặng, chiều cao.

Tuổi: phân thành ba nhóm tuổi: 60-69 tuổi, 70 đến 79 tuổi, từ 80 tuổi trở lên.

Giới tính: phân thành hai nhóm nam và nữ.

Chỉ số khối cơ thể (BMI): đánh giá chỉ số khối cơ thể theo khuyến cáo của Tổ chức y tế thế giới WHO.

Chẩn đoán hội chứng dễ bị tổn thương.

Chẩn đoán hội chứng dễ bị tổn thương theo tiêu chuẩn Fried sửa đổi:

Hội chứng dễ bị tổn thương được đánh giá theo tiêu chuẩn của Fried sửa đổi, bao gồm năm tiêu chí:

\section{a. Giảm cân không chủ ý:}

Giảm cân không chủ ý trên 4,5 kg trong năm vừa qua bằng câu hỏi:

“Trong năm qua, ông/bà có bị sụt hơn 4,5 kg không chủ ý (nghĩa là không phải do chế độ ăn kiêng hoặc tập thể dục)"? 
Hoặc (Cân nặng trong năm trước - Cân nặng hiện tại)/ Cân nặng trong năm trước $\geq 0,05$.

Nếu đối tượng nghiên cứu đáp ứng một trong hai điều kiện trên thì được tính là một tiêu chí cho hội chứng dễ bị tổn thương.

b. Giảm cơ lực:

Giảm cơ lực được đánh giá bằng đo cơ lực tay. Dụng cụ đo là áp lực kế cầm tay Jamar $5030 \mathrm{~J} 1$, đơn vị đo tính bằng kilôgam $(\mathrm{kg})$. Nghiên cứu viên sẽ cho đối tượng nghiên cứu ngồi thẳng, vai khép, cẳng tay để thoải mái, khuỷu tay gập $90^{\circ}$ so với cẳng tay, hướng dẫn đối tượng nghiên cứu bóp thật mạnh vào tay nắm của máy đo áp lực kế, trong quá trình bóp động viên đối tượng nghiên cứu cố gắng bóp hết sức có thể. Thực hiện đo cơ lực mỗi tay hai lần và lấy kết quả cao nhất. Nếu cơ lực tay của đối tượng nghiên cứu thấp hơn ngũ phân vị thấp nhất (đã điều chỉnh theo giới và chỉ số khối cơ thể) thì được tính là một tiêu chí trong chẩn đoán hội chứng dễ bị tổn thương.

\section{c. Sức bền và năng lượng kém:}

Sức bền và năng lượng kém: Tự báo cáo về tình trạng kiệt sức, xác định bằng hai câu hỏi trong thang điểm tự báo cáo trầm cảm CES-D. ( Center for Epidemiologic Studies Depression Scale). Đối tượng nghiên cứu trả lời có tình trạng kiệt sức từ ba ngày trở lên trong một tuần cho một trong hai câu hỏi được tính là một tiêu chí trong chẩn đoán hội chứng dễ bị tổn thương.

\section{d. Tốc độ đi bộ chậm:}

Đánh giá dựa trên thời gian đi bộ 15 bước $(4,57 \mathrm{~m})$ với tốc độ bình thường. Những người tham gia được yêu cầu đi bộ "nhanh nhất nhưng vẫn thấy an toàn". Thời gian đi bộ được so sánh với mức cơ bản đã điều chỉnh theo giới tính và chiều cao. Nếu thời gian đi bộ lớn hơn 20\% mức cơ bản cũng như những đối tượng không thể thực hiện các bài kiểm tra được tính là một tiêu chí cho hội chứng dễ bị tổn thương.

e. Mức hoạt động thể lực thấp:

Tổng số kilocalo tiêu hao trong mỗi tuần được tính toán dựa trên bộ câu hỏi đánh giá hoạt động thể lực RAPA(Rapid Assessment of Physical Activity). ${ }^{8}$ Những đối tượng nghiên cứu trả lời "Tôi ít khi hoặc không bao giờ làm bất kỳ hoạt động thể chất nào" được coi là ít vận động, hoặc không hoạt động thể chất; đánh giá này xấp xỉ tứ phân vị thấp nhất $(26 \%)$ của hoạt động thể lực.

Khi đối tượng nghiên cứu có từ ba trong số năm tiêu chí trở lên thì xác định là có hội chứng dễ bị tổn thương. Đối tượng nghiên cứu có từ một đến hai tiêu chí là tiền hội chứng dễ bị tổn thương. Đối tượng nghiên cứu không có tiêu chí nào là không có hội chứng dễ bị tổn thương.

\section{Xử lý số liệu}

Số liệu được thu thập và xử lý bằng phần mềm SPSS 17.0. Các biến định lượng được thể hiện dưới dạng trung bình \pm độ lệch chuẩn. Các tần suất được trình bày theo tỷ lệ \%. Sự khác biệt được coi là có ý nghĩa thống kê khi $p<0,05$.

\section{4. Đạo đức nghiên cứu}

Tất cả các đối tượng nghiên cứu sẽ được giải thích cụ thể về mục đích của nghiên cứu và đồng ý tự nguyện tham gia vào nghiên cứu. Đảm bảo tính bí mật thông tin nghiên cứu. Nghiên cứu nhằm bảo vệ và nâng cao sức khỏe cho người cao tuổi, không nhằm mục đích nào khác.

\section{KẾT QUẢ}

Trong tống số 389 đối tượng nghiên cứu có 183 bệnh nhân nữ chiếm 47\% thấp hơn so với 206 bệnh nhân nam chiếm 53\%. Tỷ lệ nam / nữ $=1,125 / 1$. Sự khác biệt không có ý nghĩa thống kê với $p>0,05$. Tuổi trung bình của các 
bệnh nhân là 79,1 $\pm 8,9$. Thấp nhất là 60 tuổi và cao nhất là 101 tuổi, trong đó nhóm từ 60 đến 69 tuổi chiếm tỷ lệ thấp nhất là $18 \%$, nhóm lớn hơn 80 tuổi chiếm tỷ lệ cao nhất $54,8 \%$. Chỉ số khối cơ thể trung bình của 389 bệnh nhân tham gia nghiên cứu tại Khoa Cấp cứu Bệnh viện Lão khoa Trung Ương là $20,89 \pm 3,27$. Nhóm bệnh nhân có chỉ số khối cơ thể bình thường chiếm tỷ lệ cao nhất $71,5 \%$. Nhóm bệnh nhân có tình trạng quá cân và béo phì chiếm tỷ lệ thấp nhất 10\% (Bảng 1).

Bảng 1. Đặc điểm chung $(\mathrm{n}=389)$

\begin{tabular}{|c|c|c|c|}
\hline \multicolumn{2}{|c|}{ Biến số } & \multirow{2}{*}{$\frac{\text { Số bệnh nhân }}{206}$} & \multirow{2}{*}{$\frac{\text { Tỉ lệ \% }}{53}$} \\
\hline \multirow{2}{*}{ Giới } & Nam & & \\
\hline & Nũ & 183 & 47 \\
\hline \multirow{3}{*}{ Nhóm tuổi } & $60-69$ & 70 & 18 \\
\hline & $70-79$ & 106 & 27,2 \\
\hline & $\geq 80$ & 213 & 54,8 \\
\hline \multirow{3}{*}{ BMI } & Thiếu cân $(<18,5)$ & 72 & 18,5 \\
\hline & Bình thường $(18,5$ - 24,9) & 278 & 71,5 \\
\hline & Quá cân và béo phì ( $\geq 25)$ & 39 & 10 \\
\hline \multicolumn{2}{|c|}{ Tuổi trung bình (Trung bình \pm độ lệch chuẩn) } & \multicolumn{2}{|c|}{$79,1 \pm 8,9$} \\
\hline \multicolumn{2}{|c|}{$\begin{array}{l}\text { Chỉ số đa bệnh lý Charlson trung bình } \\
\text { (Trung bình } \pm \text { độ lệch chuẩn) }\end{array}$} & \multicolumn{2}{|c|}{$3,55 \pm 1,95$} \\
\hline
\end{tabular}

Trong 389 bệnh nhân nghiên cứu có 266 bệnh nhân có Hội chứng dễ bị tổn thương chiếm 68,4\%; 73 bệnh nhân có tiền Hội chứng dễ bị tổn thương chiếm 18,8\% và 50 bệnh nhân không có Hội chứng dễ bị tổn thương chiếm 12,8\% (Biểu đồ 1).

$\mathrm{n}=389$

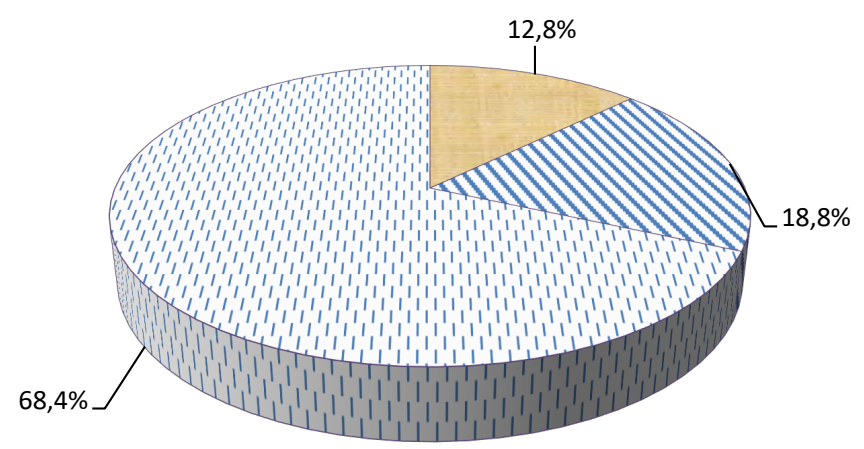

$\square$ Không có HCDBTT

母 Tiền HCDBTT

$\square$ HCDBTT

Biểu đồ 1. Tỉ lệ HCDBTT ( $n=389)$

Trong 389 bệnh nhân nghiên cứu của chúng tôi, các tiêu chí thành phần của hội chứng dễ bị tổn thương thì tốc độ đi bộ chậm là thường gặp nhất chiếm 85,5\%, mức hoạt động thể lực thấp chiếm $68,9 \%$. Giảm cân không chủ ý và sức bền và năng lượng kém chiếm tỷ lệ ngang nhau là $63,2 \%$, giảm cơ lực chiếm tỷ lệ 24,2\% (Biểu đồ 2). 


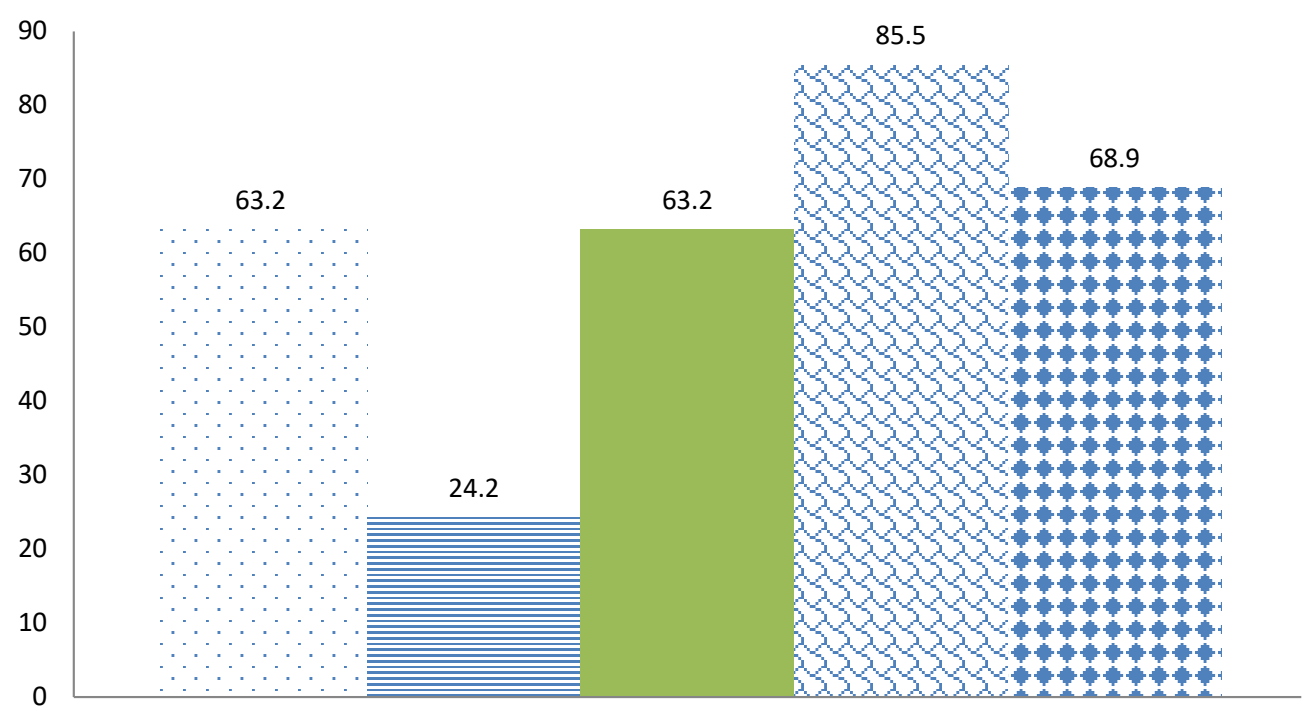

Tỉ lệ \%

Các thành phần trong hội chứng dễ bị tổn thương

$\begin{array}{ll}\text { - Giảm cân không chủ ý } & \equiv \text { Giảm cơ lực } \\ \text { ¿ Tốc độ đi bộ chậm } & \text { Mức hoạt động thể lực thấp }\end{array}$

Biểu đồ 2. Đặc điểm các tiêu chí thành phần xác định HCDBTT ( $n=389)$

Tỷ lệ bệnh nhân có hội chứng dễ bị tổn thương tăng dần theo tuổi. Nhóm bệnh nhân từ 80 tuổi trở lên có hội chứng dễ bị tổn thương cao nhất chiếm $82,2 \%$, có mối liên quan mật thiết giữa mức độ của hội chứng dễ bị tổn thương và tuổi (với p < 0,0001). (Bảng 2)

Bảng 2. Liên quan giữa các mức độ của hội chứng dễ bị tổn thương và nhóm tuổi ( $n=389$ )

\begin{tabular}{cccc}
\hline $\begin{array}{c}\text { Nhóm tuổi } \\
\text { (Tuổi) }\end{array}$ & $\begin{array}{c}\text { Không có HCDBTT } \\
\mathbf{n}(\%)\end{array}$ & $\begin{array}{c}\text { Tiền } \\
\text { HCDBTT } \\
\mathbf{n}(\%)\end{array}$ & $\begin{array}{c}\text { Có } \\
\text { HCDBTT } \\
\mathbf{n}(\%)\end{array}$ \\
\hline $60-69$ & $29(41,4 \%)$ & $19(27,1 \%)$ & $22(31,4 \%)$ \\
\hline $70-79$ & $14(13,2 \%)$ & $23(21,7 \%)$ & $69(65,1 \%)$ \\
\hline 780 & $7(3,3 \%)$ & $31(14,6 \%)$ & $175(82,2 \%)$ \\
\hline Tổng & $50(12,8 \%)$ & $73(18,8 \%)$ & $266(68,4 \%)$ \\
\hline
\end{tabular}

Trong 389 bệnh nhân nghiên cứu, có 123 bệnh nhân nữ có hội chứng dễ bị tổn thương chiếm $67,2 \%$, ít hơn bệnh nhân nam là 143 chiếm $69,4 \%$. Mặt khác số bệnh nhân nữ tiền hội chứng dễ bị tổn thương chiếm 20,8\% lại cao hơn số bệnh nhân nam (17\%), tuy nhiên không có mối liên quan giữa các mức độ hội chứng dễ bị tổn thương và giới (với p > 0,05) (Bảng 3). 
Bảng 3. Mối liên quan giưra mức độ HCDBTT với giới tính (n=389)

\begin{tabular}{ccccc}
\hline Giới tính & $\begin{array}{c}\text { Không có HCDBTT } \\
\mathbf{n}(\%)\end{array}$ & $\begin{array}{c}\text { Tiền } \\
\text { HCDBTT } \\
\mathbf{n}(\%)\end{array}$ & $\begin{array}{c}\text { Có } \\
\text { HCDBTT } \\
\mathbf{n}(\%)\end{array}$ & $\mathbf{P}$ \\
\hline Nứ & $22(12,0 \%)$ & $38(20,8 \%)$ & $123(67,2 \%)$ & 0,6 \\
\hline Nam & $28(13,6 \%)$ & $35(17,0 \%)$ & $143(69,4 \%)$ & \\
\hline
\end{tabular}

\section{BÀN LUẬN}

Hội chứng dễ bị tổn thương là một hội chứng lão khoa thường gặp ở người cao tuổi, tỷ lệ này lại càng cao hơn nhiều đặc biệt là đối tượng người cao tuổi đang điều trị tại khoa cấp cứu và điều trị tích cực. Để khảo sát Hội chứng dễ bị tổn thương ở đối tượng này, chúng tôi đã tiến hành nghiên cứu trên 389 bệnh nhân đang điều trị tại Khoa Cấp cứu của Bệnh viện Lão khoa Trung Ương, bằng phương pháp mô tả cắt ngang.

Trong tổng số 389 đối tượng nghiên cứu của chúng tôi có 183 bệnh nhân nữ chiếm 47\%, thấp hơn so với 206 bệnh nhân nam chiếm 53\%. Tỷ lệ nam/nữ $=1,125 / 1$. Khi so sánh như nhau ta có $p=0,26>0,05$ sự khác biệt không có ý nghĩa thống kê, tỷ lệ nam và nữ là như nhau trong 389 bệnh nhân nghiên cứu của chúng tôi. Khác với nghiên cứu của Chang và cộng sự (2011), tại Đài Loan thì $53,8 \%$ là nữ và $46,2 \%$ là nam, ${ }^{9}$ nghiên cứu của Oliveira và cộng sự (2013) có $50,5 \%$ là nư và $49,5 \%$ là nam, ${ }^{10}$ nghiên cứu của Nguyễn Xuân Thanh (2015) có bệnh nhân nữ là $56,8 \%$, nam là 43,2\%. ${ }^{11}$ Nhưng sự khác biệt này của các tác giả cũng không có ý nghĩa thống kê.

Tuổi trung bình của các bệnh nhân cao tuổi trong nghiên cứu của chúng tôi là 79,1 \pm 8,9 . Thấp nhất là 60 tuổi và cao nhất là 101 tuổi, trong đó nhóm từ 60 đến 69 tuổi chiếm tỷ lệ thấp nhất là $18 \%$. Nhóm lớn hơn 80 tuổi chiếm tỷ lệ cao nhất $54,8 \%$. Trong nghiên cứu của Chang và cộng sự tại Đài Loan (tuổi trung bình là $71,1 \pm 3,8) .{ }^{9}$ Một nghiên cưu khác tại Ấn Độ, tuổi trung bình của đối tượng nghiên cứu là $66,4 \pm 6,27$. Tác giả Oliveira nghiên cứu tại một Bệnh viện ở Brazil có độ tuổi trung bình là $74,5 \pm 6,8$. $^{10}$ Ở nghiên cứu của Nguyễn Xuân Thanh trên đối tượng điều trị nội khoa tại Bệnh viện Lão khoa Trung Ương thì tuổi trung bình là $76,15 \pm 8,891,{ }^{11}$ thấp hơn so với nhóm đối tượng nghiên cứu của chúng tôi. Nhóm 80 tuổi trở lên cũng chiếm tỷ lệ cao nhất 40,8\% thấp hơn trong nghiên cứu của chúng tôi là $54,8 \%$, nhóm 60 đến 69 tuổi chiếm tỷ lệ thấp nhất $26,7 \%$, còn của chúng tôi là $18 \%$.

Trong 389 bệnh nhân nghiên cứu có 266 bệnh nhân có hội chứng dễ bị tổn thương chiếm 68,4\%. Có 73 bệnh nhân tiền hội chứng dễ bị tổn thương chiếm $18,8 \%$ và 50 bệnh nhân không có hội chứng dễ bị tổn thương chiếm 12,8\%. Ghi nhận trên các nghiên cứu ở các quốc gia và đối tượng khác nhau, thì tỷ lệ hội chứng dễ bị tổn thương cũng khác nhau rất nhiều từ $4 \%$ đến $59,1 \%{ }^{6}$ Trong các đối tượng bệnh nhân nội trú là từ 15 đến $50 \%$. Theo Stiffler và cộng sự, hội chứng dễ bị tổn thương khá phổ biến ở các bệnh nhân đến khám và điều trị tại Khoa Cấp cứu (20\%). ${ }^{12}$ Trong một nghiên cứu khác tại Bệnh viện Dublin, Ireland cho thấy tỷ lệ hội chứng dễ bị tổn thương là $75 \%$ trong số các bệnh nhân điều trị tại Khoa Cấp cứu, giống như nghiên cứu của chúng tôi là $68,4 \%$. Khác với 
nghiên cứu của tác giả Nguyễn Xuân Thanh trên đối tượng bệnh nhân điều trị bệnh nội khoa ở người cao tuổi, thì bệnh nhân có hội chứng dễ bị tổn thương là 35,4\%. Tiền hội chứng dễ bị tổn thương là 40,1\% và không có hội chứng này là $24,5 \% .^{11}$ Như vậy tỷ lệ hội chứng dễ bị tổn thương trong nghiên cứu của chúng tôi có tỷ lệ khá cao là $68,4 \%$, sự khác biệt này có thể là đối tượng của chúng tôi là những bệnh nhân chiếm quá nửa là trên 80 tuổi, đang mắc một bệnh cấp tính cần chăm sóc đặc biệt tại Khoa Cấp cứu - Điều trị tích cực và có chỉ số đa bệnh lý Charlson cao như trong nghiên cứu này.

Tỷ lệ bệnh nhân có hội chứng dễ bị tổn thương tăng dần theo tuổi. Nhóm bệnh nhân từ 80 tuổi trở lên có hội chứng dễ bị tổn thương cao nhất chiếm $82,2 \%$, tiếp theo là nhóm từ 70 - 79 tuổi chiếm $65,1 \%$ và nhóm 60 - 69 tuổi chiếm 31,4\%. Còn ở tiền hội chứng dễ bị tổn thương thì lại ngược lại, tuổi càng cao thì tỷ lệ bị tiền hội chứng này càng giảm. Có lẽ một phần lớn số bệnh nhân trong nhóm này đã chuyển sang nhóm bị hội chứng dễ bị tổn thương. Trong nhóm không bị hội chứng dễ bị tổn thương thì tỷ lệ nghịch so với nhóm tuổi. Có liên quan mật thiết giữa mức độ của hội chứng dễ bị tổn thương với sự gia tăng của tuổi (với $p<0,001$ ). Nghiên cứu của chúng tôi cũng giống như những nghiên cứu khác, của Reis và cộng sự, ${ }^{13}$ của Mello, ${ }^{14}$ của Nguyễn Xuân Thanh (2015), ${ }^{11}$ cùng quan điểm sự xuất hiện của hội chứng dễ bị tổn thương liên quan mật thiết với sự gia tăng theo tuổi, đặc biệt ở đối tượng người cao tuổi.

\section{KÉT LUẬN}

Tỉ lệ bệnh nhân tại khoa Cấp cứu mắc hội chứng dễ bị tổn thương khá cao đặc biệt trên nhóm bệnh nhân trên 80 tuổi. Do vậy cần sàng lọc thường quy hội chứng dễ bị tổn thương trên người cao tuổi điều trị tại khoa cấp cứu.

\section{TÀI LIẸU THAM KHẢO}

1. UNFPA Vietnam. Già hóa dân số và người cao tuổi ở Việt Nam: thực trạng, dự báo và gợi ý chính sách. http://vietnam.unfpa.org. Accessed December 3, 2016.

2. Fried LP, Tangen CM, Walston J. Cardiovascular Health Study Collaborative Research Group... Frailty in older adults: evidence for a phenotype. The Journals of Gerontology. Series A, Biological Sciences and Medical Sciences. 2001; 56(3): M146-156.

3. Hamerman D. Toward an understanding of frailty. Annals of Internal Medicine. 1999; 130(11): 945-950.

4. Wilber ST, Blanda, Gerson LW. Does functional decline prompt emergency department visits and admission in older patients? Academic Emergency Medicine: Official Journal of the Society for Academic Emergency Medicine. 2006; 13(6): 680-682.

5. Stiffler KA, Finley A, Midha S, Wilber ST. Frailty assessment in the emergency department. The Journal of Emergency Medicine. 2013; 45(2): 291-298.

6. Collard RM, Boter H, Schoevers RA., Oude Voshaar RC... Prevalence of frailty in community-dwelling older persons: a systematic review. Journal of the American Geriatrics Society, 2012; 60(8): 1487-1492.

7. WHO. Physical status: the use and interpretation of anthropometry. . WHO. http://www.who.int/childgrowth/publications/ physical_status. Accessed December 3, 2016.

8. Topolski TD, LoGerfo J, Patrick DL. The Rapid Assessment of Physical Activity (RAPA) among older adults. Preventing Chronic Disease. 2006; 3(4): A118.

9. Chang Cl, Chan DC, Kuo KN. Prevalence and Correlates of Geriatric Frailty in a Northern Taiwan Community. Journal of the Formosan 
Medical Association. 2011; 110(4): 247-257.

10. Oliveira DR, Bettinelli LA, Pasqualotti A. Prevalence of frailty syndrome in old people in a hospital institution. Revista Latino-Americana De Enfermagem. 2013; 21(4): 891-898.

11. Nguyễn Xuân Thanh. Hội chứng dễ bị tổn thương (Frailty) và các yếu tố liên quan trên bệnh nhân cao tuổi điều trị tại Bệnh viện Lão Khoa Trung Ương. Luận văn tốt nghiệp thạc sĩ y khoa, Trường Đại Học Y Hà Nội. 2015.

12. Walston J, Hadley EC, Ferrucci L. Research agenda for frailty in older adults: toward a better understanding of physiology and etiology: summary from the American Geriatrics
Society/National Institute on Aging Research Conference on Frailty in Older Adults. Journal of the American Geriatrics Society 2006; 54(6): 991-1001.

13. Reis Júnior WM, Carneiro JA, Coqueiro R. Pre-frailty and frailty of elderly residents in a municipality with a low Human Development Index. Revista Latino-Americana De Enfermagem. 2014; 22(4): 654-661.

14. Mello AC, Engstrom EM, Alves LC. Health-related and socio-demographic factors associated with frailty in the elderly: a systematic literature review. Cadernos De Saude Publica. 2014; 30(6): 1143-1168.

\section{Summary}

\section{PREVALENCE OF FRAILTY AMONG OLDER PATIENTS IN EMERGENCY DEPARTMENT AT NATIONAL GERIATRIC HOSPITAL}

Frailty syndrome is common in older people. Thus this study aims to evaluate the prevalence of frailty syndrome in older patient treated in Emergency Department, National Geriatric Hospital. This is a cross-sectional study with older inpatients over 60 years old in Emergency Department, National Geriatric Hospital from October, 2015 to October 2016. Data were collected by using variables included general information and frailty criteria diagnosis (loss weight, decrease hand grip strength, exhausted, low physical activity and low walking speed). A total 389 participants with mean of age was $79,1 \pm 8,9$. The prevalence of frailty in older patients was $68.4 \%$. Percentage of low walking speed was the highest domain in 5 domains of frailty. Patients were $\geq 80$ years old have highest proportion of frailty with $82.2 \%(p<0.05)$. The prevalence of frailty at older patients was high, specially in the group of patients over 80 years old. Therefore, it is necessary to routine screening of frailty syndrome in older patient treated in Emergency Department.

Keywords: frailty, older patients, Emergency Department, Vietnam. 